\title{
Natural history of subclinical hypothyroidism in children and adolescents and potential effects of replacement therapy: a review
}

\author{
Alice Monzani, Flavia Prodam, Anna Rapa, Stefania Moia, Valentina Agarla, Simonetta Bellone and Gianni Bona
} Division of Pediatrics, Department of Health Sciences, Università del Piemonte Orientale 'A. Avogadro', Via Solaroli 17, 28100 Novara, Italy

(Correspondence should be addressed to G Bona; Email: gianni.bona@maggioreosp.novara.it)

\begin{abstract}
Objective: Subclinical hypothyroidism $(\mathrm{SH})$ is quite common in children and adolescents. The natural history of this condition and the potential effects of replacement therapy need to be known to properly manage SH. The aim of this review is to analyze: i) the spontaneous evolution of SH, in terms of the rate of reversion to euthyroidism, the persistence of $\mathrm{SH}$, or the progression to over hypothyroidism; and ii) the effects of replacement therapy, with respect to auxological data, thyroid volume, and neuropsychological functions.

Methods: We systematically searched PubMed, Cochrane, and EMBASE (1990-2012) and identified 39 potentially relevant articles of which only 15 articles were suitable to be included.

Results and conclusions: SH in children is a remitting process with a low risk of evolution toward overt hypothyroidism. Most of the subjects reverted to euthyroidism or remained SH, with a rate of evolution toward overt hypothyroidism ranging between 0 and $28.8 \%$, being $50 \%$ in only one study (nine articles). The initial presence of goiter and elevated thyroglobulin antibodies, the presence of celiac disease, and a progressive increase in thyroperoxidase antibodies and TSH value predict a progression toward overt hypothyroidism. Replacement therapy is not justified in children with SH but with TSH 5-10 mIU/l, no goiter, and negative antithyroid antibodies. An increased growth velocity was observed in children treated with levothyroxine (L-T $\mathrm{T}_{4}$; two articles). $\mathrm{L}_{-} \mathrm{T}_{4}$ reduced thyroid volume in $25-100 \%$ of children with SH and autoimmune thyroiditis (two studies). No effects on neuropsychological functions (one study) and posttreatment evolution of SH (one study) were reported.
\end{abstract}

European Journal of Endocrinology 168 R1-R11

\section{Introduction}

Subclinical hypothyroidism (SH) is biochemically defined as a serum TSH concentration above the statistically defined upper limit of the reference range when serum-free thyroxine $\left(\mathrm{fT}_{4}\right)$ concentration is within its reference range $(1,2)$. The clinical presentation varies widely, ranging from no manifestations to clear signs or symptoms of hypothyroidism. SH prevalence in the adult population is reported to be $1-10 \%$, being higher in the elderly population, in females, and in white subjects $(3,4,5)$. In the pediatric population, SH prevalence is reported to be slightly lower than $2 \%$, even if epidemiological studies concerning childhood and adolescence are scanty. Therefore, $\mathrm{SH}$ is quite a common disorder in pediatric patients, and both primary care physicians and pediatric endocrinologists frequently face the decision of what to do regarding these children.

In order to adequately manage a case of $\mathrm{SH}$, it is of paramount importance to know how this condition will evolve and when it should be treated. The natural course of SH in adults seems to progress to overt hypothyroidism (reduced circulating thyroid hormones) in proportions ranging from $<1$ up to $20 \%$ according to different studies $(1,3,4)$, with higher rates of progression in patients with higher baseline serum TSH concentration, elevated antithyroid autoantibodies, and a higher degree of hypoechogenicity at thyroid ultrasound $(6,7)$. In addition to the risk of progression to overt hypothyroidism, in the decision to treat or not a condition of $\mathrm{SH}$, the clinician should also consider the systemic consequences of leaving the hyperthyrotropinemia untreated. In adults, SH has been associated with an increased risk for coronary and other heart diseases, peripheral arterial diseases $(8,9,10,11)$, depression (12), and various biochemical abnormalities, including elevated LDL cholesterol, increased serum prolactin concentrations, and a negative influence on the hemostatic profile $(8,13,14,15,16)$. On the other hand, the risks of an overtreatment should be likewise considered. 
An overtreated SH could bring on subclinical hyperthyroidism, which has been reported to be responsible for significant bone loss in postmenopausal women $(17,18)$ and atrial fibrillation in older patients (19). Moreover, potential benefits of higher TSH levels such as longevity and a lower all-cause mortality have been suggested by recent studies $(20,21)$.

Studies regarding the natural history of SH and its consequences in childhood are lacking and very few studies have examined the effects of levothyroxine $\left(\mathrm{L}-\mathrm{T}_{4}\right)$ replacement therapy in young people with SH. The aim of this review is to summarize what is known about the natural course of $\mathrm{SH}$ in children and adolescents and the potential effects of a replacement therapy.

\section{Materials and methods}

\section{Literature search}

We systematically searched PubMed, Cochrane, and EMBASE (January 1990-July 2012) to identify studies evaluating the natural history of SH and the efficacy of replacement therapy with $\mathrm{L}-\mathrm{T}_{4}$ in children and adolescents.

The search terms used included 'SH', 'hyperthyrotropinemia', 'child\$' (or 'adolescent\$'), and 'history' or 'course' or 'evolution' and 'treatment' or 'therapy'. These terms were combined in various ways to generate a wide search. In addition, we checked the references of eligible articles for further papers that were not captured by our search strategy and corresponded with authors when a full-length article was not available directly online or when relevant information was missing in the paper.

\section{Inclusion and exclusion criteria}

For the analysis of the natural history of $\mathrm{SH}$, we included only full-length articles that met the following predetermined criteria: i) longitudinal or retrospective studies regarding the natural history of $\mathrm{SH}$ in the pediatric age; ii) studies evaluating the spontaneous evolution of $\mathrm{SH}$, in terms of rate of reversion to euthyroidism, persistence of $\mathrm{SH}$, or progression to over hypothyroidism; iii) no studies on pharmacological or lifestyle intervention that might interfere with $\mathrm{SH}$ natural evolution; iv) no studies including patients with chronic systemic diseases, genetic syndromes, or taking concomitant therapy with either lithium salts, antiepileptic agents, glucocorticoids, or iodinated drugs; and v) studies in the English language.

For the analysis of the potential effects of replacement therapy on SH, we included only full-length articles that met the following predetermined criteria: i) clinical trials performed in pediatric patients reporting on the efficacy of replacement therapy with $\mathrm{L}_{-} \mathrm{T}_{4}$ in $\mathrm{SH}$; ii) no studies including patients with chronic systemic diseases, genetic syndromes, or taking concomitant therapy with either lithium salts, antiepileptic agents, glucocorticoids, or iodinated drugs; and iii) studies in the English language.

\section{Data extraction and synthesis}

A form was generated to register whether individual studies met eligibility criteria and to collect data regarding the study design and methodological quality. Three investigators independently reviewed and extracted data from the papers according to the predetermined criteria. Any difference in opinion about the studies was resolved by discussion between the investigators.

\section{Outcome measures}

In the analysis of the studies concerning the natural history of SH, we focused on the following measures: i) rate of reversion to euthyroidism (normal TSH and thyroid hormone levels); ii) rate of persistence of $\mathrm{SH}$ (normal thyroid hormone levels with stably elevated or even raised TSH levels); and iii) rate of progression to overt hypothyroidism (high TSH levels with reduced thyroid hormone levels). Owing to the low number of studies analyzing the effects of replacement therapy for SH and the lack of common outcomes, the therapeutic efficacy of $\mathrm{L}-\mathrm{T}_{4}$ was evaluated by reporting the specific results of each study.

\section{Analysis}

Selection bias and lack of common outcome measures were some of the problems that prevented a proper metaanalysis. Although this review is not a meta-analysis, we critically assessed the literature and tried to identify high-quality studies. In the evaluation of replacement therapy, wherever possible, preference was given to randomized controlled trials and longitudinal studies. Very few reports, however, had such characteristics; therefore, we included other types of clinical trials. Moreover, we examined whether the control group was appropriate and whether overtreatment was avoided. Lastly, we evaluated whether correct statistical analyses were applied in the selected studies.

\section{Results}

\section{Natural history of SH in children and adolescents}

The literature search we performed identified 27 potentially relevant articles. After reviewing titles, abstracts, and the full-length texts, nine articles were selected for closer assessment and then included in our analysis $(22,23,24,25,26,27,28,29,30)$. They are summarized in Table 1. 


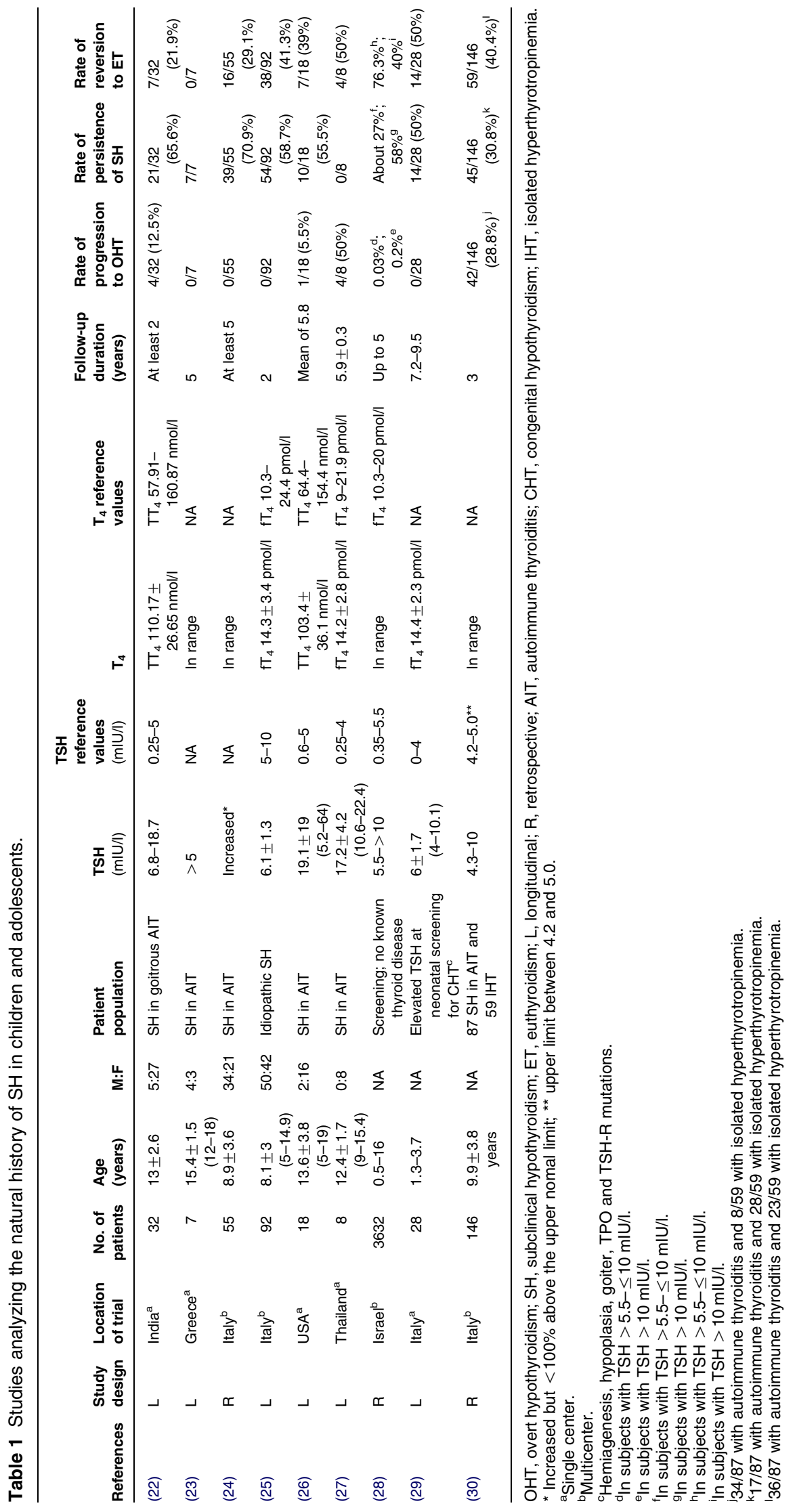


Of the nine selected studies, six were longitudinal trials $(22,23,25,26,27,29)$ and three were retrospective $(24,28,30)$. Five were single center studies $(22,23,26,27,29)$ and four were multicenter studies $(24,25,28,30)$. Overall, data from a total of 4018 children were reported, with most studies including a small number of subjects and only one retrospective study including a very large study population (28). In most studies, the patient population was represented by subjects with autoimmune thyroiditis, the most frequent cause of $\mathrm{SH}$ in pediatric age $(22,23,24,26,27,30)$, in one study by subjects with elevated TSH levels at newborn screening (29), in another by subjects with $\mathrm{SH}$ of unidentified origin (idiopathic SH) (25), in one by subjects with isolated hyperthyrotropinemia (30), and in another by children in a health care system who had undergone TSH determination, without any known thyroid illness (28). Children's age showed a wide range of variability, ranging from 6 months to 19 years. The follow-up duration after the diagnosis of $\mathrm{SH}$ varied from a period of 2 to 9.5 years.

In the study by Gopalakrishnan et al. (22), out of 32 Indian children and adolescents with goitrous autoimmune thyroiditis followed for a minimum period of 2 years, seven $(21.9 \%)$ had their TSH normalized, $21(65.6 \%)$ remained in a condition of $\mathrm{SH}$, and only four (12.5\%) developed overt hypothyroidism.

Zois et al. (23) reported the persistence of $\mathrm{SH}$ in all seven Greek adolescents with autoimmune thyroiditis followed for 5 years. They also showed that thyroid hypoechogenicity and anti-thyroperoxidase (TPO-Ab) and anti-thyroglobulin antibodies (TG-Ab) increased over time.

In the retrospective multicenter study by Radetti et al. (24), out of 55 Italian children with Hashimoto's thyroiditis, during the follow-up, 16 (29.1\%) became euthyroid and the remaining 39 children remained $\mathrm{SH}$. Of those that remained SH, $16(29.1 \%)$ had a TSH value that was one- to twofold above the upper normal limit, while $23(41.8 \%)$ had a TSH value that increased more than twofold above the upper normal limit. As $\mathrm{L}_{-} \mathrm{T}_{4}$ treatment was started and patients were excluded from the study as their TSH became twofold above the upper normal limit, it was not possible to state how many children would have actually developed an overt hypothyroidism. The authors also reported that the presence of goiter and elevated TG-Abs at presentation and a progressive increase in TPO-Abs and TSH value may be predictive of the development of hypothyroidism for the group as a whole, even if none of these parameters could predict the deterioration of thyroid function in individual subjects. When analyzing the presence of signs of impaired thyroid function, the statural growth was normal during the entire observation period in all patients and no significant difference in BMI SDS was found between the patients, independent of the evolution of their thyroid function during the study period.

Wasniewska et al. (25), who followed for 2 years, 92 Italian children with 'idiopathic' SH, defined an incidental finding of elevated TSH for which all etiological causes of $\mathrm{SH}$ had been excluded. They reported that $38(41.3 \%)$ patients normalized their TSH, 54 (58.7\%) remained SH, 43 (46.7\%) with a TSH 5-10 mIU/l, and $11(12 \%)$ with an increased TSH $>10 \mathrm{mIU} / \mathrm{l}$ (10.5-15 mIU/l); however, amongst these, none developed an overt hypothyroidism. Neither TSH and $\mathrm{fT}_{4}$ values at entry nor the presence of a family history of thyroid diseases were predictive of the normalization of TSH or persistence of SH. None of the children showed any symptoms of hypothyroidism during follow-up and no changes in height and BMI were observed throughout the observation period.

Moore (26) studied 18 American patients with autoimmune thyroiditis and elevated TSH concentration, of which 11 were never treated and seven were followed for at least 1 year after the discontinuation of treatment. During the observation period, TSH normalized in seven subjects, TSH remained increased with normal $\mathrm{fT}_{4}$ levels in ten, and only one patient developed an overt hypothyroidism.

In the study by Jaruratanasirikul et al. (27), out of eight Thai girls with SH in Hashimoto's thyroiditis, after 6 years of follow-up, four (50\%) recovered normal thyroid function without any medication and the other four patients developed an overt hypothyroidism, which was treated by $\mathrm{T}_{4}$. The authors reported that goiter size remained unchanged without medication, that no clinical or biochemical markers at baseline were able to predict who will become euthyroid or hypothyroid, and that all eight SH patients achieved their final height and entered puberty at a normal age, regardless of the evolution of their thyroid function.

Lazar et al. (28) in their retrospective multicenter study analyzed a database of 121052 children aged 0.5-16 years who had a TSH measured in 2002 and were followed to 2007. They reported that about 3\% (3632 subjects) had $\mathrm{SH}$ according to the first TSH evaluation. During the 5-year follow-up, TSH values tended to normalize proportionally to the degree of the TSH elevation at the initiation of the study. In subjects with $\mathrm{TSH}>5.5-\leq 10 \mathrm{mIU} / \mathrm{l}, 73.6 \%$ normalized their TSH, about $25 \%$ maintained that range, about $2 \%$ had their $\mathrm{TSH}$ increased $>10 \mathrm{mIU} / \mathrm{l}$ but with normal $\mathrm{fT}_{4}$, and $0.03 \%$ developed an overt hypothyroidism that required medical treatment. In subjects with TSH $>10 \mathrm{mIU} / \mathrm{l}, 40 \%$ normalized their TSH, 33.1\% reduced their TSH to a value between 5.5 and $10 \mathrm{mIU} / \mathrm{l}, 24.9 \%$ maintained their TSH $>10 \mathrm{mIU} / \mathrm{l}$, and $0.2 \%$ developed an overt hypothyroidism that was treated. Predictive factors for a sustained highly elevated TSH $(>10 \mathrm{mIU} / \mathrm{l})$ were an initial TSH $>7.5 \mathrm{mIU} / \mathrm{l}$ and female gender, whereas age was not found to be a predictive factor. 
Leonardi et al. (29) studied a group of Italian children 'false positive' to neonatal screening for congenital hypothyroidism, who had normal $\mathrm{fT}_{4}$ and normal or slightly elevated TSH values at the recall examination at a mean of 22 days of life. When retested at 2-3 years of age, 28 of them had SH (TSH 4-10.1 mIU/l with normal $\mathrm{fT}_{4}$ ). Twenty of these 28 children were treated with a replacement therapy and then withdrawn from therapy 2-3 months before reevaluation. Out of the 28 children with $\mathrm{SH}$, at $4.1-6.6$ years of age, TSH was normal in nine children $(32 \%)$ and persistently elevated in the remaining $19(68 \%)$, ranging between 4 and $9.2 \mathrm{mIU} / \mathrm{l}$. At 7.2-9.5 years of age, TSH remained normal in the nine children who previously normalized their thyroid function, returned to normal in five out of 19 of the children with a previous elevated TSH value, and persisted above normal in the remaining 14 , ranging between 4.1 and $8.2 \mathrm{mIU} / \mathrm{l}$. On the whole, half of the children (14 out of 28) reverted to euthyroidism at the end of the observation period, while the rest remained SH, with none of the children developing an overt hypothyroidism. Studying thyroid morphology, the authors showed the presence of hemiagenesis, hypoplasia of one lobe, or goiter in half of these children and detected gene mutations in two children (TPO and TSH-R mutation respectively). Therefore, the authors concluded that a mild hyperthyrotropinemia at neonatal screening, in particular when these data are confirmed at a further evaluation, may be suggestive of congenital anatomic or functional anomalies of the thyroid gland. These data remain to be confirmed in further evaluations and the clinical significance resolved, as none of the studied children developed an overt hypothyroidism during the follow-up.

Finally, in the recent retrospective study by Radetti et al. (30), the natural evolution of $87 \mathrm{SH}$ children with autoimmune thyroiditis and 59 children with isolated hyperthyrotropinemia was analyzed after a 3-year period. Out of 87 children with autoimmune thyroiditis, $17(19.5 \%)$ remained stable in their SH condition, $36(41.4 \%)$ normalized their TSH, and $34(39.1 \%)$ developed an overt hypothyroidism. Out of 59 children with isolated hyperthyrotropinemia, 28 (47.5\%) remained stable in their SH condition, $23(39 \%)$ normalized their TSH, and only eight (13.5\%) developed an overt hypothyroidism. The authors also investigated possible predictive factors for the development of hypothyroidism and found that in patients with autoimmune thyroiditis, the presence of celiac disease, elevated TSH, and TPO-Abs increased the risk of developing hypothyroidism by 4-, 3.4-, and 3.5-fold respectively whereas no predictive factor was identified in patients with isolated hyperthyrotropinemia. In particular, they found that in patients with autoimmune thyroiditis, the increase in TSH levels was strongly predictive of the development of hypothyroidism.

\section{Effects of replacement therapy for $S H$ in children and adolescents}

Our literature search identified 12 potentially relevant articles. After reviewing the titles, abstracts, and the full-length articles, six were selected for a closer assessment and included in this review $(31,32,33$, $34,35,36)$. They are summarized in Table 2.

Of the six selected studies, three were retrospective trials $(32,34,35)$, one of which was a case-control study (32), and three were longitudinal trials $(31,33$, 36 ), of which one was a crossover study (where $\mathrm{L}-\mathrm{T}_{4}$ was compared with no treatment) (36). Five studies were single center studies $(31,32,34,35,36)$ and one a multicenter (33). Overall, data from a total of 202 children were reported. In two studies, the patient population was represented by subjects with an autoimmune thyroiditis $(34,35)$, in one study by subjects with both congenital and acquired $\mathrm{SH}$ of unspecified origin (36), in one study by children with mild and idiopathic SH (33), in one other by children with type 1 diabetes (32), and in another one by children with short stature (31). Children's age varied between 2.1 and 18.5 years. The treatment duration varied widely, ranging from 6 weeks to 12 years. The $\mathrm{L}_{-} \mathrm{T}_{4}$ dosage varied between 2 and $4 \mu \mathrm{g} / \mathrm{kg}$ per day, was not available in two studies $(34,36)$, and in one study the dosage per kilogram body weight was not reported (35).

The longitudinal study by Cetinkaya et al. (31) included 24 prepubertal and 15 pubertal Turkish children complaining of short stature, in which SH was diagnosed by TRH stimulation test. They received $\mathrm{L}-\mathrm{T}_{4}$ at $2 \mu \mathrm{g} / \mathrm{kg}$ per day for 1 year. After both 6 months and 1 year of treatment, growth velocity and growth velocity SDS were significantly increased in prepubertal and pubertal subjects, even if the improvement was more significant in the pubertal group. The authors reported no signs of clinical hyperthyroidism in any patient.

In the retrospective study by Chase et al. (32), 25 American children with $\mathrm{SH}$ and type 1 diabetes were matched to 25 diabetic controls. Five of the 25 cases were pubertal and 20 prepubertal. The 25 diabetic children with $\mathrm{SH}$ received $\mathrm{L}-\mathrm{T}_{4}$ at $2-4 \mu \mathrm{g} / \mathrm{kg}$ per day for 2 years, with TSH and $\mathrm{T}_{4}$ determinations at least twice yearly to adjust the dosage in order to keep their levels within the normal range. The authors showed a significant improvement in growth velocity after $\mathrm{L}-\mathrm{T}_{4}$ treatment in prepubertal children compared with diabetic controls, with this improvement more significant in children with higher TSH values at entry. No significant difference was found in growth velocity between pubertal children and diabetic controls and in height Z-scores between all treated children and diabetic controls.

In the longitudinal study by Wasniewska et al. (33), 69 Italian patients with mild (TSH $5-10 \mathrm{mIU} / \mathrm{l}$ ) and idiopathic SH were treated with $\mathrm{L}_{-} \mathrm{T}_{4}$ for 2 years and 


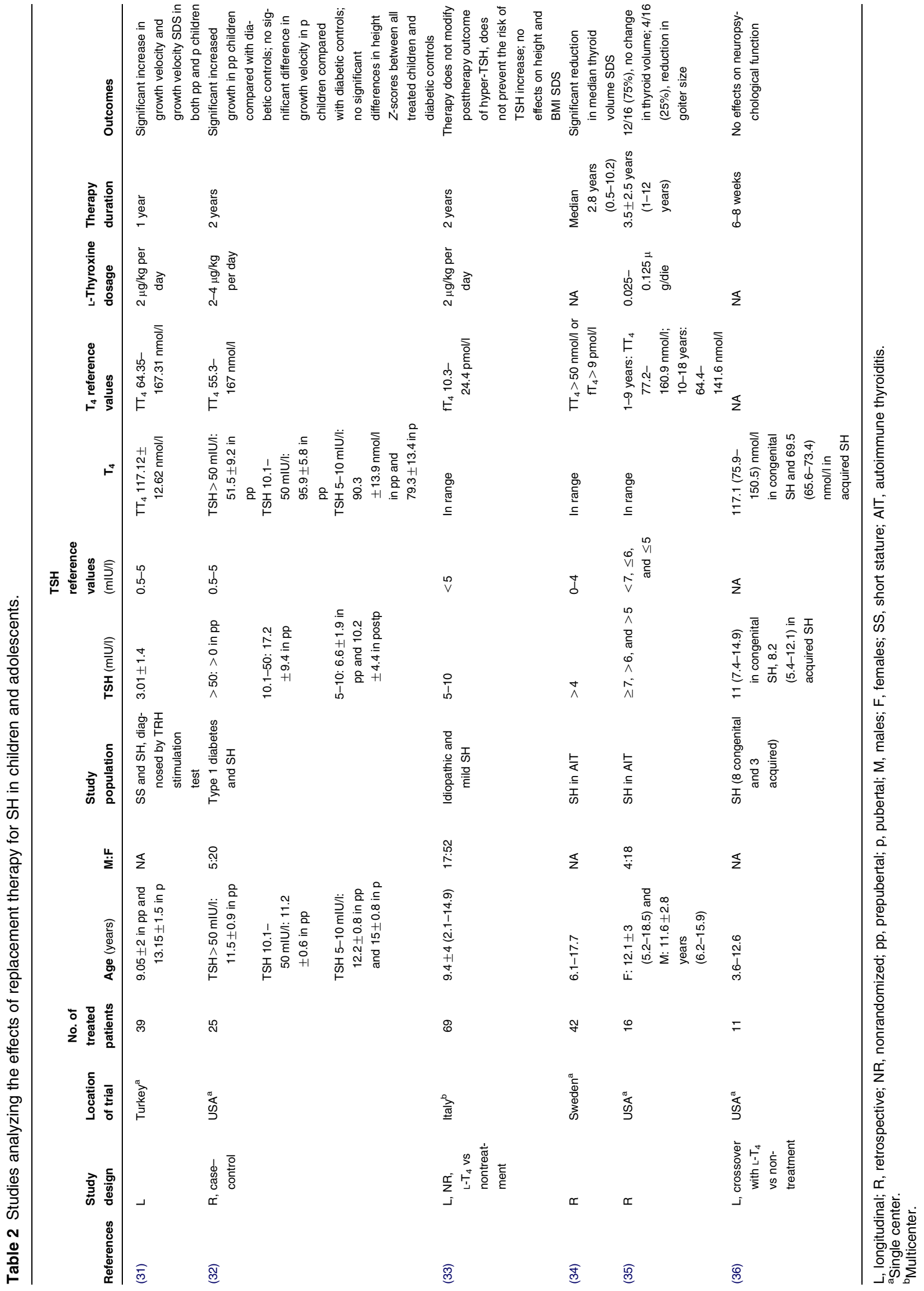


evaluated 3 months after therapy withdrawal. The starting dose was $2 \mu \mathrm{g} / \mathrm{kg}$ per day. The 69 treated children were compared with a cohort of 92 untreated children matched for age and thyroid function followed for 2 years. At the end of follow-up, the prevalence of those who normalized, maintained, or increased $>10 \mathrm{mIU} / \mathrm{l}$ their TSH value was similar between the treated and untreated children. In treated children, TSH values at baseline were predictive of TSH values 3 months after treatment withdrawal. No effects of therapy on height and BMI SDS were found; however, growth velocity was not reported.

Svensson et al. (34) in their retrospective study analyzed data in 42 Swedish children with $\mathrm{SH}$ and autoimmune thyroiditis who were treated with $\mathrm{L}_{-} \mathrm{T}_{4}$. A significant reduction in median thyroid volume SDS was seen at each 2-year assessment during the therapy. Correlations were found between the reduction in thyroid volume SDS and the thyroid volume SDS at baseline, the treatment duration, and TSH and $\mathrm{T}_{4}$ levels at baseline. No complications with the $\mathrm{L}_{-} \mathrm{T}_{4}$ treatment were reported during the study period.

The retrospective study by Rother et al. (35) reported the effects of $\mathrm{L}_{-} \mathrm{T}_{4}$ in 16 American children with autoimmune thyroiditis treated for a period ranging from 1 to 12 years. In $75 \%$ of them, no changes in thyroid volume were observed, whereas in the remaining $25 \%$ a reduction in goiter size took place.

In the study by Ajiaz et al. (36), the possible effects of $\mathrm{T}_{4}$ therapy on cognitive functions of children with $\mathrm{SH}$ were investigated. Indeed, no effects on neuropsychological functions were shown in the 6- to 8-week observation period; in particular, no improvement in problems of attention was reported.

\section{Discussion}

The first aim of our review was to critically assess the studies evaluating the natural course of SH in childhood. The main limits of this analysis were the low number of patients included in most of the studies and the high heterogeneity of the study populations. Despite such limits, the studies analyzed as a whole seem to show that $\mathrm{SH}$ in children and adolescents is a benign and remitting process with a low risk of evolution toward an overt hypothyroidism. Indeed, most of the subjects included in the studies reverted to euthyroidism or remained SH, sometimes with an increase in TSH values. The rate of development of an overt hypothyroidism ranged between $0 \%$ in three studies $(23,24,25)$ and $28.8 \%$, with only one study (27) reporting an evolution toward an overt hypothyroidism in a half of the eight investigated children.

Notably, when signs of impaired thyroid function were investigated, height, BMI, and the age of puberty were found to be normal and no clinical manifestations of hypothyroidism were reported, regardless of the evolution of thyroid function. In accordance with these data, a recent Italian study analyzing growth and intellectual parameters in a cohort of 36 children with persistent idiopathic SH followed longitudinally for a period of 2.0-9.3 years demonstrated no alterations in growth, bone maturation, BMI status, and cognitive functions in presence of persistently elevated TSH values (37). Therefore, thyroid hormones involved in growth and neurocognitive development seem to work properly, regardless of the persistently elevated $\mathrm{TSH}$, in the absence of replacement therapy.

When analyzing which factors may possibly be predictive of the natural course of SH, Radetti et al. $(24,30)$ reported that the initial presence of goiter and elevated TG-Abs, the presence of celiac disease, and a progressive increase in TPO-Abs and TSH value may be predictive of progression toward an overt hypothyroidism. Lazar et al. (28) reported that an initial TSH higher than $7.5 \mathrm{mIU} / \mathrm{l}$ and the female gender are predictive factors for a sustained highly elevated TSH.

The results regarding the natural history of $\mathrm{SH}$ in children differ in some aspects from those reported in elderly patients with SH (16). Studies in adults and the elderly with idiopathic $\mathrm{SH}$ or $\mathrm{SH}$ in autoimmune thyroiditis reported that the progression toward overt hypothyroidism is quite common, with a low rate of spontaneous normalization of TSH values $(4,6,38)$. On the other hand, similar to the elderly, the presence of goiter, higher initial TSH levels, and positive antithyroid antibodies were reported to be predictive factors of evolution toward thyroid failure in children, even if these data are not unanimously endorsed (24).

A special mention should be given to the results by Leonardi et al. (29) who reported a high persistence of $\mathrm{SH}$ in children 'false positive' at neonatal screening for congenital hypothyroidism. In fact, even if none of the children developed an overt hypothyroidism, pediatricians should take into account that a newborn with transient hyperthyrotropinemia at birth could be at risk of developing SH later on in childhood.

Finally, many studies were excluded from our analyses because rates of persistence of $\mathrm{SH}$, reversion to euthyroidism, or progression to overt hypothyroidism according to our outcome measures were not available $(39,40,41,42,43,44,45,46)$. All these studies were focused on essential overweight or obesity, a clinical condition frequently associated with SH (47). However, none of them analyzed the natural course of SH without any intervention. Indeed, a TSH normalization is generally reported after weight loss but the mechanisms underlying such thyroid hormonal changes in obese children are far from clear. Furthermore, in the pediatric setting, there are no controlled studies looking at the outcomes of obese children with elevated TSH levels treated with $\mathrm{T}_{4}$ vs placebo, with data regarding the beneficial effects of replacement therapy still lacking.

As most studies in the pediatric age have shown that SH is often a remitting or self-limiting process, the point of 
when to treat with replacement therapy still remains a matter of debate. In the studies included in the second part of this review, the efficacy of $\mathrm{L}^{-} \mathrm{T}_{4}$ treatment is shown in respect to three main outcomes, i.e. auxological parameters, goiter size, and neuropsychological functions.

Three studies analyzed the effect of $\mathrm{L}_{-} \mathrm{T}_{4}$ on growth $(31,32,33)$. Two of them $(31,32)$ found an increased growth velocity in treated children, even if Chase et al. (32) showed this result exclusively in prepubertal children. However, it has to be underlined that in the study populations, $\mathrm{SH}$ was not an isolated condition. On the other hand, Wasniewska et al. (33) did not evaluate growth velocity but reported no differences in height and BMI between treated and untreated children. Similar results were found in the abstract by Zen et al. (48), who reported no differences in the growth velocity SDS and height SDS in 20 treated and 26 untreated children with short stature and $\mathrm{SH}$.

Two studies focused on the effect on $\mathrm{L}_{-} \mathrm{T}_{4}$ on thyroid volume $(34,35)$ and showed contrasting results. In the study by Svensson et al. (34), a significant reduction in thyroid volume of children with $\mathrm{SH}$ and autoimmune thyroiditis was seen. On the contrary, Rother et al. (35) reported a significant reduction in goiter size only in $25 \%$ of their children with $\mathrm{SH}$ and autoimmune thyroiditis. One possible explanation for this different outcome may be the different age at diagnosis of the subjects included in the two studies. In particular, in the study by Rother et al. (49), the children were peripubertal and it is well known that a rapid increase in thyroid volume normally takes place during puberty. Moreover, it should be noted that the estimation of thyroid volume was made by palpation in one study (35) and by ultrasonography in the other (34).

Finally, only one study investigated the effect of $\mathrm{L}_{-} \mathrm{T}_{4}$ on neurocognitive function (36). Even if $\mathrm{T}_{4}$ therapy is known to have a significant long-term impact on behavioral, locomotor, speech, hearing, and cognitive abilities in children with congenital hypothyroidism as the developing brain is more sensitive to thyroid hormone deprivation (50), no effects of $\mathrm{L}_{-} \mathrm{T}_{4}$ on neuropsychological functions of children with $\mathrm{SH}$ were reported in this study. It has to be mentioned that children with $\mathrm{SH}$ had attention problems when compared with healthy controls and that these problems were subclinical in the sense that they were not previously reported by parents but were only detected by neuropsychological tests. One possible explanation for the lack of effects reported is the small sample size analyzed and the short intervention period. On the whole, no clinical signs of hyperthyroidism due to an overtreatment of $\mathrm{SH}$ were reported in any of the reviewed studies. To our knowledge, there are no studies in children up until now, which have investigated the potential effects of replacement therapy for SH or untreated hyperthyrotropinemia on cardiovascular function, lipid profile, or bone mass, that have been reported to be affected by TSH levels in adults $(8,9,10,11,13,17,18)$.
Indeed, the decision regarding the treatment of $\mathrm{SH}$ continues to be controversial. The debate over treatment of SH in adulthood has persisted for years and review articles have been published both for $(51,52)$ and against treatment $(53,54)$. In 2004 and 2005, two expert panels came to different conclusions about the management of $\mathrm{SH}$ in adults $(1,55)$. One expert panel (1) concluded that patients with normal $\mathrm{fT}_{4}$ and TSH $>10 \mathrm{mIU} / \mathrm{l}$ may be treated, whereas it advised follow-up of subjects with TSH in the range of 4.5-10.0 $\mathrm{mIU} / \mathrm{l}$ because of insufficient evidence to support treatment in these latter patients and because of the concern of overtreatment. On the other hand, a consensus statement jointly published by the American Association of Clinical Endocrinologists, the American Thyroid Association, and The Endocrine Society (55) concluded that treatment of SH patients with TSH levels of 4.5-10 mIU/l was appropriate, as the lack evidence of benefit does not necessarily mean a lack of benefit. Although both panels did not address the issue of SH in the pediatric population, taking into account the low rate of progression to an overt hypothyroidism, treatment of SH in children should be indicated in the presence of clinical signs or symptoms of impaired thyroid function or goiter or TSH $>10 \mathrm{mIU} / \mathrm{l}$. $\mathrm{L}_{-} \mathrm{T}_{4}$ therapy may be beneficial when $\mathrm{SH}$ is associated with short stature and impaired growth velocity or increased thyroid volume. According to the available evidence, hyperthyroidism due to an overtreatment of SH should be considered an infrequent condition in the pediatric age group. In children with $\mathrm{SH}$ but with no goiter, negative antithyroid antibodies and TSH 5-10 mIU/l replacement therapy are not justified, both because of the low risk to develop an overt hypothyroidism and that they could simply be euthyroid outliers, representing $2.5 \%$ of normal individuals whose TSH values are above $97.5^{\text {th }}$ percentile of euthyroid distribution. It has to be taken into account that euthyroid outliers could be carriers of polymorphisms or mutations in genes of the thyroid hormone pathway such as TSH receptor, dual oxidase 2 (DUOX2), phosphodiesterase $8 \mathrm{~B}$, and TPO $(56,57,58,59,60)$.

\section{Concluding remarks}

i) $\mathrm{SH}$ in children seems to be a remitting process with a low risk of evolution toward overt hypothyroidism.

ii) The initial presence of goiter and elevated TG-Abs and a progressive increase in TPO-Abs and TSH values predict a progression toward overt hypothyroidism.

iii) There is no clear evidence on the beneficial effects of $\mathrm{L}_{-} \mathrm{T}_{4}$ on growth and thyroid volume in $\mathrm{SH}$ due to insufficient data.

iv) No effects on neuropsychological functions were reported. 
v) Replacement therapy is not justified in children with SH but with TSH 5-10 mIU/l, no goiter, and negative antithyroid antibodies.

vi) Further randomized double-blind studies are needed to clearly evaluate the effects of replacement therapy on growth, goiter, neuropsychological, and cardiovascular outcomes.

\section{Declaration of interest}

The authors declare that there is no conflict of interest that could be perceived as prejudicing the impartiality of the review reported.

\section{Funding}

This review did not receive any specific grant from any funding agency in the public, commercial or not-for-profit sector.

\section{Author contribution statement}

A Monzani, F Prodam, and G Bona revised the literature, analyzed the selected studies, and drafted the manuscript. A Rapa, S Moia, VAgarla, and S Bellone critically revised the manuscript.

\section{Acknowledgements}

The authors would like to thank Dr Gillian Walker for English language revision of the manuscript.

\section{References}

1 Surks MI, Ortiz E, Daniels GH, Sawin CT, Col NF, Cobin RH, Franklyn JA, Hershman JM, Burman KD, Denke MA et al. Subclinical thyroid disease: scientific review and guidelines for diagnosis and management. Journal of the American Medical Association 2004291 228-238. (doi:10.1001/jama.291.2.228)

2 Cooper DS \& Biondi B. Subclinical thyroid disease. Lancet 2012 379 1142-1154. (doi:10.1016/S0140-6736(11)60276-6)

3 Canaris GJ, Manowitz NR, Mayor G \& Ridgway EC. The Colorado thyroid disease prevalence study. Archives of Internal Medicine 2000 160 526-534. (doi:10.1001/archinte.160.4.526)

4 Parle JV, Franklyn JA, Cross KW, Jones SC \& Sheppard MC. Prevalence and follow-up of abnormal thyrotrophin (TSH) concentrations in the elderly in the United Kingdom. Clinical Endocrinology 199134 77-83. (doi:10.1111/j.1365-2265.1991. tb01739.x)

5 Hollowell JG, Staehling NW, Flanders WD, Hannon WH, Gunter EW, Spencer CA \& Braverman LE. Serum TSH, T(4), and thyroid antibodies in the United States population (1988 to 1994): National Health and Nutrition Examination Survey (NHANES III). Journal of Clinical Endocrinology and Metabolism 2002 87 489-499. (doi:10.1210/jc.87.2.489)

6 Vanderpump MP, Tunbridge WM, French JM, Appleton D, Bates D, Clark F, Grimley Evans J. Hasan DM, Rodgers H et al. The incidence of thyroid disorders in the community: a twenty-year follow-up of the Whickham survey. Clinical Endocrinology 199543 55-68. (doi:10.1111/j.1365-2265.1995.tb01894.x)

7 Marcocci C, Vitti P, Cetani F, Catalano F, Concetti R \& Pinchera A. Thyroid ultrasonography helps to identify patients with diffuse lymphocytic thyroiditis who are prone to develop hypothyroidism. Journal of Clinical Endocrinology and Metabolism 199172 209-213. (doi:10.1210/jcem-72-1-209)
8 Althaus BU, Staub JJ, Ryff-De Leche A, Oberhansli A \& Stahelin HB. LDL/HDL-changes in subclinical hypothyroidism: possible risk factors for coronary heart disease. Clinical Endocrinology $1988 \mathbf{2 8}$ 157-163. (doi:10.1111/j.1365-2265.1988.tb03651.x)

9 Nanchen D, Gussekloo J, Westendorp RG, Stott DJ, Jukema JW, Trompet S, Ford I, Welsh P, Sattar N, Macfarlane PW, Mooijaart SP, Rodondi N, de Craen AJ \& PROSPER Group. Subclinical thyroid dysfunction and the risk of heart failure in older persons at high cardiovascular risk. Journal of Clinical Endocrinology and Metabolism 201297 852-861. (doi:10.1210/jc.2011-1978)

10 Hak AE, Pols HA, Visser TJ, Drexhage HA, Hofman A \& Witteman JC. Subclinical hypothyroidism is an independent risk factor for atherosclerosis and myocardial infarction in elderly women: the Rotterdam Study. Annals of Internal Medicine 2000 132 270-278. (doi:10.1059/0003-4819-132-4-20000215000004)

11 Rodondi N, den Elzen WP, Bauer DC, Cappola AR, Razvi S, Walsh JP, Asvold BO, Iervasi G, Imaizumi M, Collet TH et al. Subclinical hypothyroidism and the risk of coronary heart disease and mortality. Journal of the American Medical Association 2010 304 1365-1374. (doi:10.1001/jama.2010.1361)

12 Haggerty JJ Jr, Stern RA, Mason GA, Beckwith J, Morey CE \& Prange AJ Jr. Subclinical hypothyroidism: a modifiable risk factor for depression? American Journal of Psychiatry 1993 $150508-510$.

13 Diekman T, Lansberg PJ, Kastelein JJ \& Wiersinga WM. Prevalence and correction of hypothyroidism in a large cohort of patients referred for dyslipidemia. Archives of Internal Medicine 1995155 1490-1495. (doi:10.1001/archinte.1995.00430140052004)

14 Staub JJ, Althaus BU, Engler H, Ryff AS, Trabucco P, Marquardt K, Burckhardt D, Girard J \& Weintraub BD. Spectrum of subclinical and overt hypothyroidism: effect on thyrotropin, prolactin, and thyroid reserve, and metabolic impact on peripheral target tissues. American Journal of Medicine 199292 631-642. (doi:10.1016/ 0002-9343(92)90782-7)

15 Muller B, Tsakiris DA, Roth CB, Guglielmetti M, Staub JJ \& Marbet GA. Haemostatic profile in hypothyroidism as potential risk factor for vascular or thrombotic disease. European Journal of Clinical Investigation 200131 131-137. (doi:10.1046/j.13652362.2001.00777.x)

16 Biondi B \& Cooper DS. The clinical significance of subclinical thyroid dysfunction. Endocrine Reviews 200829 76-131. (doi:10.1210/er.2006-0043)

17 Uzzan B, Campos J, Cucherat M, Nony P, Boissel JP \& Perret GY. Effects on bone mass of long-term treatment with thyroid hormones: a meta-analysis. Journal of Clinical Endocrinology and Metabolism 199681 4278-4289. (doi:10.1210/jc.81.12.4278)

18 Faber J \& Galloe AM. Changes in bone mass during prolonged subclinical hyperthyroidism due to L-thyroxine treatment: a metaanalysis. European Journal of Endocrinology 1994130 350-356. (doi:10.1530/eje.0.1300350)

19 Sawin CT, Geller A, Wolf PA, Belanger AJ, Baker E, Bacharach P, Wilson PW, Benjamin EJ \& D'Agostino RB. Low serum thyrotropin concentrations as a risk factor for atrial fibrillation in older persons. New England Journal of Medicine 1994331 1249-1252. (doi:10.1056/NEJM199411103311901)

20 Atzmon G, Barzilai N, Hollowell JG, Surks MI \& Gabriely I. Extreme longevity is associated with increased serum thyrotropin. Journal of Clinical Endocrinology and Metabolism $2009 \mathbf{9 4}$ 1251-1254. (doi:10.1210/jc.2008-2325)

21 Rozing MP, Houwing-Duistermaat JJ, Slagboom PE, Beekman M, Frölich M, de Craen AJ, Westendorp RG \& van Heemst D. Familial longevity is associated with decreased thyroid function. Journal of Clinical Endocrinology and Metabolism 201095 4979-4984. (doi:10.1210/jc.2010-0875)

22 Gopalakrishnan S, Chugh PK, Chhillar M, Ambardar VK, Sahoo M \& Sankar R. Goitrous autoimmune thyroiditis in a pediatric population: a longitudinal study. Pediatrics 2008122 670-674. (doi:10.1542/peds.2008-0493) 
23 Zois C, Stavrou I, Svarna E, Seferiadis K \& Tsatsoulis A. Natural course of autoimmune thyroiditis after elimination of iodine deficiency in northwestern Greece. Thyroid 200616 289-293. (doi:10.1089/thy.2006.16.289)

24 Radetti G, Gottardi E, Bona G, Corrias A, Salardi S, Loche S \& Study Group for Thyroid Diseases of the Italian Society for Pediatric Endocrinology and Diabetes (SIEDP/ISPED). The natural history of euthyroid Hashimoto's thyroiditis in children. Journal of Pediatrics 2006149 827-832. (doi:10.1016/j.jpeds.2006.08.045)

25 Wasniewska M, Salerno M, Cassio A, Corrias A, Aversa T, Zirilli G, Capalbo D, Bal M, Mussa A \& De Luca F. Prospective evaluation of the natural course of idiopathic subclinical hypothyroidism in childhood and adolescence. European Journal of Endocrinology $2009160417-421$. (doi:10.1530/EJE-08-0625)

26 Moore DC. Natural course of 'subclinical' hypothyroidism in childhood and adolescence. Archives of Pediatrics $\mathcal{E}$ Adolescent Medicine 1996150 293-297. (doi:10.1001/archpedi.1996. 02170280063012 )

27 Jaruratanasirikul S, Leethanaporn K, Khuntigij P \& Sriplung H. The clinical course of Hashimoto's thryoiditis in children and adolescents: 6 years longitudinal follow-up. Journal of Pediatric Endocrinology \& Metabolism 200114 177-184. (doi:10.1515/ JPEM.2001.14.2.177)

28 Lazar L, Frumkin RB, Battat E, Lebenthal Y, Phillip M \& Meyerovitch J. Natural history of thyroid function tests over 5 years in a large pediatric cohort. Journal of Clinical Endocrinology and Metabolism 200994 1678-1682. (doi:10.1210/jc.2008-2615)

29 Leonardi D, Polizzotti N, Carta A, Gelsomino R, Sava L, Vigneri R \& Calaciura F. Longitudinal study of thyroid function in children with mild hyperthyrotropinemia at neonatal screening for congenital hypothyroidism. Journal of Clinical Endocrinology and Metabolism 2008 93 2679-2685. (doi:10.1210/jc.2007-2612)

30 Radetti G, Maselli M, Buzi F, Corrias A, Mussa A, Cambiaso P, Salerno M, Cappa M, Baiocchi M, Gastaldi R, Minerba L \& Loche S. The natural history of the normal/mild elevated TSH serum levels in children and adolescents with Hashimoto's thyroiditis and isolated hyperthyrotropinaemia: a 3-year follow-up. Clinical Endocrinology $2012 \mathbf{7 6}$ 394-398. (doi:10.1111/j.1365-2265. 2011.04251.x)

31 Cetinkaya E, Aslan A, Vidinlisan S \& Ocal G. Height improvement by L-thyroxine treatment in subclinical hypothyroidism. Pediatrics International: Official Journal of the Japan Pediatric Society 200345 534-537. (doi:10.1046/j.1442-200X.2003.01786.x)

32 Chase HP, Garg SK, Cockerham RS, Wilcox WD \& Walravens PA. Thyroid hormone replacement and growth of children with subclinical hypothyroidism and diabetes. Diabetic Medicine 1990 7 299-303. (doi:10.1111/j.1464-5491.1990.tb01393.x)

33 Wasniewska M, Corrias A, Aversa T, Valenzise M, Mussa A, De Martino L, Lombardo F, De Luca F \& Salerno M. Comparative evaluation of therapy with L-thyroxine versus no treatment in children with idiopathic and mild subclinical hypothyroidism. Hormone Research in Pediatrics 201277 376-381. (doi:10.1159/ 000339156 )

34 Svensson J, Ericsson UB, Nilsson P, Olsson C, Jonsson B, Lindberg B \& Ivarsson SA. Levothyroxine treatment reduces thyroid size in children and adolescents with chronic autoimmune thyroiditis. Journal of Clinical Endocrinology and Metabolism $2006 \mathbf{9 1}$ 1729-1734. (doi:10.1210/jc.2005-2400)

35 Rother KI, Zimmerman D \& Schwenk WF. Effect of thyroid hormone treatment on thyromegaly in children and adolescents with Hashimoto disease. Journal of Pediatrics 1994124 599-601. (doi:10.1016/S0022-3476(05)83141-5)

36 Aijaz NJ, Flaherty EM, Preston T, Bracken SS, Lane AH \& Wilson TA. Neurocognitive function in children with compensated hypothyroidism: lack of short term effects on or off thyroxin. BMC Endocrine Disorders 20066 2. (doi:10.1186/14726823-6-2)

37 Cerbone M, Bravaccio C, Capalbo D, Polizzi M, Wasniewska M, Cioffi D, Improda N, Valenzise M, Bruzzese D, De Luca F \& Salerno M. Linear growth and intellectual outcome in children with long-term idiopathic subclinical hypothyroidism. European Journal of Endocrinology 2011164 591-597. (doi:10.1530/EJE10-0979)

38 Huber G, Staub JJ, Meier C, Mitrache C, Guglielmetti M, Huber P \& Braverman LE. Prospective study of the spontaneous course of subclinical hypothyroidism: prognostic value of thyrotropin, thyroid reserve, and thyroid antibodies. Journal of Clinical Endocrinology and Metabolism 200287 3221-3226. (doi:10.1210/jc.87.7.3221)

39 Reinehr T \& Andler W. Thyroid hormones before and after weight loss in obesity. Archives of Disease in Childhood 200287 320-323. (doi:10.1136/adc.87.4.320)

40 Reinehr T, de Sousa G \& Andler W. Hyperthyrotropinemia in obese children is reversible after weight loss and is not related to lipids. Journal of Clinical Endocrinology and Metabolism 200691 3088-3091. (doi:10.1210/jc.2006-0095)

41 Reinehr T, Isa A, de Sousa G, Dieffenbach R \& Andler W. Thyroid hormones and their relation to weight status. Hormone Research 200870 51-57. (doi:10.1159/000129678)

42 Shalitin S, Yackobovitch-Gavan M \& Phillip M. Prevalence of thyroid dysfunction in obese children and adolescents before and after weight reduction and its relation to other metabolic parameters. Hormone Research 200971 155-161. (doi:10.1159/000197872)

43 Grandone A, Santoro N, Coppola F, Calabrò P, Perrone L \& Del Giudice EM. Thyroid function derangement and childhood obesity: an Italian experience. BMC Endocrine Disorders 2010108. (doi:10.1186/1472-6823-10-8)

44 Aeberli I, Jung A, Murer SB, Wildhaber J, Wildhaber-Brooks J, Knöpfli BH \& Zimmermann MB. During rapid weight loss in obese children, reductions in TSH predict improvements in insulin sensitivity independent of changes in body weight or fat. Journal of Clinical Endocrinology and Metabolism 201095 5412-5418. (doi:10.1210/jc.2010-1169)

45 Marras V, Casini MR, Pilia S, Carta D, Civolani P, Porcu M, Uccheddu AP \& Loche S. Thyroid function in obese children and adolescents. Hormone Research in Pediatrics 201073 193-197. (doi:10.1159/000284361)

46 Radetti G, Longhi S, Baiocchi M, Cassar W \& Buzi F. Changes in lifestyle improve body composition, thyroid function, and structure in obese children. Journal of Endocrinological Investigation 201235 281-285. (doi:10.3275/7763)

47 Pacifico L, Anania C, Ferraro F, Andreoli GM \& Chiesa C. Thyroid function in childhood obesity and metabolic comorbidity. Clinica Chimica Acta 2012413 396-405. (doi:10.1016/j.cca.2011.11.013)

48 Zen VL, Czepielewski MA, de Paula LP \& Schwerz JC. Thyroxin replacement therapy does not improve growth velocity in children with subclinical hypothyroidism and short stature Proceedings of the 91st Annual Meeting of the Endocrine Society, Washington, DC, USA, June 2009.

49 Fleury Y, Van Melle G, Woringer V, Gaillard RC \& Portmann L. Sex dependent variations and timing of thyroid growth during puberty. Journal of Clinical Endocrinology and Metabolism $20018 \mathbf{8 6}$ 750-754. (doi:10.1210/jc.86.2.750)

50 Rovet J. Long-term neuropsychological sequelae of early-treated congenital hypothyroidism: effects in adolescence. Acta Paediatrica 199988 88-95. (doi:10.1111/j.1651-2227.1999.tb01168.x)

51 McDermott MT \& Ridgway EC. Subclinical hypothyroidism is mild thyroid failure and should be treated. Journal of Clinical Endocrinology and Metabolism 200186 4585-4590. (doi:10.1210/jc.86.10.4585)

52 Owen PJ \& Lazarus JH. Subclinical hypothyroidism: the case for treatment. Trends in Endocrinology and Metabolism $2003 \mathbf{1 4}$ 257-261. (doi:10.1016/S1043-2760(03)00108-5)

$53 \mathrm{Chu}$ JW \& Crapo LM. The treatment of subclinical hypothyroidism is seldom necessary. Journal of Clinical Endocrinology and Metabolism 200186 4591-4599. (doi:10.1210/jc.86.10.4591)

54 Vanderpump M. Subclinical hypothyroidism: the case against treatment. Trends in Endocrinology and Metabolism 200314 262-266. (doi:10.1016/S1043-2760(03)00103-6)

55 Gharib H, Tuttle RM, Baskin HJ, Fish LH, Singer PA \& McDermott MT. Consensus statement: subclinical thyroid 
dysfunction: a joint statement on management from the American Association of Clinical Endocrinologists, the American Thyroid Association and the Endocrine Society. Journal of Clinical Endocrinology and Metabolism 200590 581-585. (doi:10.1210/ jc.2004-1231)

56 Rapa A, Monzani A, Moia S, Vivenza D, Bellone S, Petri A, Teofoli F, Cassio A, Cesaretti G, Corrias A et al. Subclinical hypothyroidism in children and adolescents: a wide range of clinical, biochemical, and genetic factors involved. Journal of Clinical Endocrinology and Metabolism 200994 2414-2420. (doi:10.1210/jc.20090375)

57 De Marco G, Agretti P, Montanelli L, Di Cosmo C, Bagattini B, De Servi M, Ferrarini E, Dimida A, Freitas Ferreira AC, Molinaro A et al. Identification and functional analysis of novel dual oxidase 2 (DUOX2) mutations in children with congenital or subclinical hypothyroidism. Journal of Clinical Endocrinology and Metabolism 201196 E1335-E1339. (doi:10.1210/jc.2010-2467)

58 Grandone A, Perrone L, Cirillo G, Di Sessa A, Corona AM, Amato A, Cresta N, Romano T \& Miraglia del Giudice E. Impact of phosphodiesterase 8B gene rs4704397 variation on thyroid homeostasis in childhood obesity. European Journal of Endocrinology 2012166 255-260. (doi:10.1530/EJE-11-0703)

59 Peeters RP, van der Deure WM \& Visser TJ. Genetic variation in thyroid hormone pathway genes; polymorphisms in the $\mathrm{TSH}$ receptor and the iodothyronine deiodinases. European Journal of Endocrinology 2006155 655-662. (doi:10.1530/eje. $1.02279)$

60 Turkkahraman D, Alper OM, Aydin F, Yildiz A, Pehlivanoglu S, Luleci G, Akcurin S \& Bircan I. Final diagnosis in children with subclinical hypothyroidism and mutation analysis of the thyroid peroxidase gene (TPO). Journal of Pediatric Endocrinology \& Metabolism 200922 845-851. (doi:10.1515/JPEM.2009.22.9.845)

Received 30 July 2012

Revised version received 12 September 2012

Accepted 18 September 2012 